\title{
External counterpulsation for the treatment of patients with refractory angina
}

\author{
Rovshan Huseyn Alakbarov ${ }^{1}$, Tofig Shahmur Jahangirov ${ }^{1}$, Orazbek Sakhov ${ }^{2}$, Sholpan Zhangelova ${ }^{3}$
}

${ }^{\text {I} C a r d i a c ~ F a i l u r e ~ D e p a r t m e n t, ~ J . A b d u l l a y e v ~ S c i e n t i f i c ~}$ Research Institute of Cardiology, Baku, Republic of Azerbaijan

${ }^{2} X$-Ray Surgery Department, City Heart Center, Almaty, Republic of Kazakhstan

${ }^{3} № 2$ Internal Medicine Department, Asfendiyarov Kazakh National Medical University, Almaty, Republic of Kazakhstan

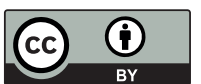

This work is licensed under a Creative Commons Attribution 4.0 International License

\section{Received: 2018-05-25}

Accepted: 2018-06-13

UDC: 616.1

J Clin Med Kaz 2018;2(48):14-21

Corresponding Author: Rovshan Huseyn Alakbarov, J.Abdullayev Scientific Research Institute of Cardiology, Baku, Republic of Azerbaijan. Tel.: +994503301752 E-mail: 1047@mail.ru

\begin{abstract}
Despite the great advances in conventional medical and invasive treatment of patients with coronary heart disease, a significant number of these patients continues to have a resistant to standard therapy angina pectoris. Many of these patients are not candidates for subsequent myocardial revascularisation procedures for many reasons, and optimal medical treatment is not allowed to effectively control the symptoms of angina pectoris. To treat this category of patients, a large number of different treatment methods have been proposed. External counterpulsation is one of the methods of treatment of patients with refractory angina.
\end{abstract}

Key words: coronary heart disease, refractory angina, external counterpulsation

СЫРТҚЫ КОНТРПУЛЬСАЦИЯНЫ РЕФРАКТЕРЛІ СТЕНОКАРДИЯСЫ БАР НАУҚАСТАРДА ЕМДЕУ ҮШІН ҚОЛДАНУ Алекперов Р.Г. ${ }^{1}$, Джахангиров Т.Ш. ${ }^{1}$, Сахов О.С. ${ }^{2}$, Жангелова Ш.Б. ${ }^{3}$

'Жүрек жеткіліксіздігі бөлімі, Д..Абдуллаев атындағы Кардиология ғылыми-зерттеу институты, Баку, Әзірбайжан Республикасы

${ }^{2}$ Рентген-хирургия бөлімі, Қалалық кардиологиялық орталық, Алматы, Қазақстан Республикасы

${ }^{3} № 2$ Ішкі аурулар кафедрасы, С.Ж. Асфендияров атындағы Қазақ ұлттық медицина университеті, Алматы, Қазақстан Республикасы

\section{ТҰЖЫРЫМДАМА}

Жүректің ишемиялық ауруымен ауыратын науқастардың инвазивты және медикаментозды емдеу тәсілдерінің үлкен жетістіктеріне қарамастан, белгілі бір санаттағы науқастарда стенокардияға (жүректің демікпелі ұстама ауруы) стандартты терапиясына резистенттік байқалады. Осы науқастар көптеген себептермен миокард реваскулиризация рәсімедеріне кандидат болып табылмайды, ал оңтайлы медикаментозды терапия стенокардия симптомдарын тиімді бақыламайды. Осы санаттағы науқастарды емдеу үшін әр түрлі емдеу әдістері ұсынылды. Сыртқы контрпульсация рефррактерлі стенокардиясы бар науқастарда емдік әдістерінің бірі болып табылады.

Негізгі сөздер: жүректің ишемиялық ауруы, рефрактерлі стенокардия, сыртқы контрпульсация

\section{ПРИМЕНЕНИЕНАРУЖНОЙКОНТРПУЛЬСАЦИИДЛЯЛЕЧЕНИЯПАЦИЕНТОВСРЕФРАКТЕРНОЙСТЕНОКАРДИЕЙ} Алекперов Р.Г. ${ }^{1}$, Джахангиров Т.Ш. ${ }^{1}$, Сахов О.С. ${ }^{2}$, Жангелова Ш.Б. ${ }^{3}$

'Отделение сердечной недостаточности, Научно-исследовательский институт кардиологии им. Дж. Абдуллаева, Баку, Азербайджанская Республика

${ }^{2}$ Отделение рентген-хирургии, Городской кардиологический центр, Алматы, Республика Казахстан

${ }^{3}$ Кафедра внутренних болезней №2, Казахский Национальный медицинский университет им. С.Д. Асфендиярова, Алматы, Республика Казахстан

\section{PЕЗЮME}

Несмотря на большие успехи в медикаментозном и инвазивном лечении пациентов с ишемической болезнью сердца, у определенной категории пациентов наблюдается резистентная к стандартной терапии стенокардия. Многие из этих пациентов не являются кандидатами для последующих процедур реваскуляризации миокарда по многим причинам, а оптимальная медикаментозная терапия не позволяет эффективно контролировать симптомы стенокардии. Для лечения этой категории пациентов было предложено большое количество различных методов лечения. Наружная контрпульсация является одним из методов лечения пациентов с рефрактерной стенокардией.

Ключевые слова: ишемическая болезнь сердца, рефрактерная стенокардия, наружная контрпульсация 


\section{Введение}

По данным Всемирной Организации Здравоохранения сердечно-сосудистые заболевания являются основной причиной смерти во всем мире [1]. По данным Американской Ассоциации Сердца (АНА) распространенность стенокардии в США составляет примерно 35 случаев на каждую 1000 человек [2]. Смертность больных со стабильной стенокардией напряжения достаточно высокая и составляет приблизительно 4\% в год, а у больных с нестабильной стенокардией от 7 до $8 \%$ в год [3]. Учитывая это, проблема эффективного лечения стенокардии сохраняет свою актуальность. В случаях, когда, несмотря на оптимальную медикаментозную терапию, модификацию образа жизни и выполненные процедуры реваскуляризации наблюдается 3-ий или 4-ый класс стенокардии по классификации Канадского Сердечно-сосудистого Общества (CCS), стенокардию трактуют как рефрактерную. Проблема лечения рефрактерной стенокардии становится актуальнее из года в год. Так, по данным Cheng и соавт. число больных с рефрактерной стенокардией в Канаде превышает 500 тысяч человек, а в США рефрактерная стенокардия наблюдается у 1,8 млн. больных. Основной причиной увеличения числа больных с рефрактерной стенокардией является улучшение выживаемости больных с ИБС, а также старение населения [4].

Для лечения рефрактерной стенокардии было предложено большое количество медикаментозных и немедикаментозныхметодовлечения. Для медикаментозного лечения рефрактерной стенокардии в дополнение к терапии первой линии были разработаны новые лекарственные средства с различными механизмами действия. К препаратам второй и третьей линии относятся: никорандил, ивабрадин, ранолазин, триметазидин, пергекселин, аллопуринол, молсидомин и фасудил [4]. Среди основных немедикаментозных методов лечения рефрактерной стенокардии в последние годы были предложены и изучены следующие методы лечения: усиленная наружная контрпульсация (ЕECP); методы нейростимуляции: чрескожная электронейростимуляция (TENS, SENS) и стимуляция спинного мозга (SCS); ударно-волновая терапия сердца(ESMR); трансмиокардиальная и чрескожнаялазерная реваскуляризация (TMR, PMR); имплантация редьюсера коронарного синуса, а также различные методы терапии с использованием стволовых клеток и генной инженерии [4]. Немедикаментозным методом лечения, имеющим класс рекомендаций ІІа от Европейского Общества Кардиологов (с уровнем доказательной базы В), и рекомендуемый для использования в повседневной клинической практике для лечения рефрактерной стенокардии является методика Наружной Контрпульсации (НКП) [5].

\section{История применения НКП}

Сама концепция контрпульсации берет свое начало с понимания двух важнейших основ сердечно-сосудистой гемодинамики и сердечного метаболизма, которые были исследованы в 50-х годах прошлого века. К ним относятся диастолическое усиление коронарного кровотока с целью улучшения общей коронарной перфузии и систолическая разгрузка сердечной мышцы с целью уменьшения её работы и, следовательно, потребления кислорода миокардом.

Одними из первых работ, посвященными возможности усиления коронарного кровотока посредством увеличения диастолического давления можно считать работы, выполненные выдающимся американским кардиологом, кардиохирургом Адрианом Кантровитцем (Adrian Kantrowitz) в конце 40-х, начале 50-х годов XX века. Именно тогда уже высказывались предположения о возможности улучшения коронарного кровотока методом задержки систолического давления, передаваемое в коронарное русло. Используя уравнение Пуазейля, Кантровитц математически предсказал усиление коронарного кровотока от 20 до 40\% при использовании данной методики. Им также впервые была разработана экспериментальная модель устройства, которое было испытано в опытах на собаках. Постоянно модифицируя устройство, Кантровитцу удалось экспериментальным путем получить усиление кровотока в коронарных сосудах от 22 до 53\%, и высказать предположение, что данная методика может оказаться полезной в случаях необходимости улучшения коронарного кровотока при ишемической болезни сердца (ИБС) [6].

В начале 1960-х годов различными авторами было сообщено, что снижение потребления миокардом кислорода и увеличение диастолического перфузионного давления, может быть получено путем приложения наружного давления на периферическую артериальную систему [7-9]. Фактически с этих работ и началась дальнейшая разработка устройств, основным принципом работы которых являлась наружная, неинвазивная, синхронизированная с сердечным ритмом компрессия артериальной системы нижних конечностей. Первые аппараты для наружной компрессии были гидравлическими системами, которые при компрессии одновременно сжимали всю нижнюю конечность. Конструктивно первые аппараты представляли собой два длинных цилиндра, в которые помещались ноги пациента от бедер до лодыжек. Дальнейшее развитие технологий и устройств привело к тому, что для осуществления наружной контрпульсации стали использовать гораздо менее сложные и громоздкие устройства на основе пневматических систем. Это послужило основой для развития пневматических устройств, работающих на основе последовательной (дистально-проксимальной) компрессии. Данный принцип работы реализован на всех современных аппаратах для наружной контрпульсации. Большой вклад в развитие пневматических систем для наружной контрпульсации внесли китайские ученые во главе с доктором Zheng [10].

Ранние клинические исследования наружной контрпульсации отличались друг от друга дизайном исследования и клиническим применением. Большинство работ касалось использования наружной контрпульсации для лечения острого инфаркта миокарда или кардиогенного шока, с коротким временем лечения [11-15]. Soroff и соавт в своей работе показали, что при использовании наружной контрпульсации выживаемость пациентов при кардиогенном шоке после инфаркта миокарда значимо повышается с 15\% до $45 \%(\mathrm{p}<0,01)$ [12]. Несмотря на определенные успехи применения наружной контрпульсации в лечении больных с острым инфарктом миокарда дальнейшее развитие хирургических и интервенционных методов лечения привело к тому, что интерес к этому методу лечения у большинства исследователей в США для лечения больных с острым инфарктом миокарда стал снижаться. В начале 1970-х годов было предложено использование данного метода лечения у больных со стабильной стенокардией напряжения. Так, в работе Banas было продемонстрировано использование метода наружной контрпульсации для лечения больных со стабильной стенокардией напряжения [16]. В 1983 году 
Zheng и соавт. на примере 200 пациентов со стабильной стенокардией напряжения показали, что использование 35 часового курса лечения наружной контрпульсацией приводит к длительному симптоматическому улучшению в 97\% случаев [10]. Одним из факторов, способствующим повышению интереса к наружной контрпульсации у кардиологов того времени была проблема неразрешимости реваскуляризации миокарда, когда калибр сосудов недостаточен для эффективного шунтирования. Не менее остро стоялапроблема рефрактерной стенокардии у больных, уже перенесших несколько процедур реваскуляризации миокарда, и находящихся на оптимальной медикаментозной терапии. Все эти факторы способствовали росту интереса к НКП.

Одним из первых исследований, выполненном в США на усовершенствованном пневматическом аппарате для наружной контрпульсации у больных со стабильной стенокардией напряжения, стало исследование, выполненное Lawson и соавтр., и опубликованное в 1992 году [17]. Лечение проводилось на пневматическом аппарате наружной компрессии с помощью трёх групп манжет, которые накладывались на икры, бедра и талию пациента. Использовалась синхронизированная с зубцом $\mathrm{R}$ на ЭКГ компрессия нижних конечностей с максимальным давлением воздуха в системе до 280 мм рт. ст. Лечение было начато у 18 пациентов (17 мужчин и одна женщина) с рефрактерной стенокардией. Всем пациентам был проведен 36 часовой курс лечения по 1 часу в день. Эффективность лечения была оценена стресс-тестом с таллием-201, который был выполнен до и после лечения НКП. После курса лечения все пациенты отметили уменьшение симптомов стенокардии. Проведенные после курса лечения стресстесты с таллием-201 показали, что у 12 пациентов (67\%) полностью исчезли дефекты перфузии, у 2-х пациентов дефекты перфузии сократились, а у 4-х пациентов не изменились. Таким образом, уменьшение миокардиальной ишемии, которое было оценено объективным методом исследования, было зафиксировано у 78\% пациентов $(\mathrm{p}<0,01)$. Первым крупным исследованием, которое оказало немаловажное значение на клиническое применение методики НКП, было исследование MUST-EECP, результаты которого были опубликованы в 1999-ом году [18]. Исследование MUST-EECP было многоцентровым, проспективным, рандомизированным, двойным слепым и плацебо-контролируемым, которое было выполнено в 7 университетских клиниках США. Первоначально в 1995-1997 годах в исследование было включено около 500 больных, рандомизированы были 139 пациентов. Основным критерием включения были: 1) возраст от 21 года до 81 лет; 2) наличие стенокардии по классификации Канадского Сердечно-сосудистого Общества I, II и III функционального класса; 3) положительный стресс-тест на наличие ишемии миокарда. Пациенты были разделены на 2 группы: группа активного лечения, куда первоначально было включено 72 пациента (завершили лечение 59 пациентов) и группа контроля, где было 67 пациентов (завершили лечение 65 пациентов). Все пациенты обеих групп получили 35 часовой курс лечения, причем для пациентов в основной группе во время лечения использовалось рабочее давление до 300 мм рт. ст., в то время как для пациентов группы контроля использовалось гемодинамически не эффективное низкое давление 75 мм рт.ст., которое аналогично плацебо. Все пациенты хорошо перенесли курс лечения, каких-либо серьезных осложнений выявлено не было. Результаты этого исследования показали, что у пациентов основной группы статистически значимо по сравнению с группой контроля повысилось время до возникновения депрессии ST-сегмента на 1 мм во время стресс-ЭКГ теста. Также у пациентов основной группы отмечалось снижение частоты приступов стенокардии после прохождения курса лечения.

Метод НКП стал все шире использоваться в США. Для оценки эффективности и безопасности данной методики на широком круге пациентов с разными демографическими показателями (раса, пол, возраст) в сентябре 1995 году был организован Консорциум Усиленной Наружной Контрпульсации, куда вошли более 100 различных центров НКП. В консорциум вошли клиники разного профиля: больницы, центры реабилитации, амбулаторные кабинеты врачей с различным опытом проведения процедур НКП. Для анализа были использованы данные 2289 пациентов, собранные с 84 центров. У всех пациентов отмечалась стенокардия напряжения I-IV функционального класса. После окончания курса лечения (в среднем 33,4 часа терапии НКП) у большинства пациентов $(73,4 \%)$ отмечалось снижение функционального класса стенокардии как минимум на один класс, в то время как у 26,5\% пациентов функциональный класс стенокардии не изменился. В среднем улучшение функционального класса стенокардии отмечалось с 2,78 до 1,81 ( $<<0,001)$. Эффективность лечения существенно зависела от класса стенокардии, максимальный эффект отмечался у пациентов с III или IV функциональным классом (ФК) стенокардии. У 48,9\% пациентов с IV ФК стенокардии отмечалось улучшение ФК стенокардии на 2 класса и выше, в то время как у пациентов с III ФК этот показатель был равен 34,9\%. В этом исследовании не была выявлена разница в эффективности лечения у разных центров НКП с разным опытом проведения процедур. К другим важным моментам касательно НКП, которые были получены в этом исследовании, можно отнести: 1) обоснованность 35-и часового курса лечения: у пациентов получивших меньше 35 часов терапии отмечалась меньшая эффективность НКП в снижении класса стенокардии, а у пациентов, получивших больше 35 часов терапии, не было отмечено дальнейшего улучшения ФК стенокардии; 2) не были выявлены половые различия в эффективности НКП; 3) эффективность НКП была выше у более молодых пациентов [19].

Следующим исследованием, оказавшем немаловажное значение на дальнейшее клиническое использование метода НКП было исследование Международного регистра пациентов НКП (The International EECP Patient Registry (IEPR)) [20]. Международный регистр пациентов НКП был организован в 1998 году в университете города Питтсбург, чтобы изучить клиническую эффективность, безопасность и влияние на отдаленные результаты у больных получивших курс лечения НКП. Первоначально данные касательно 978 пациентов в данный реестр прислали 43 центра, в которых было установлено соответствующее оборудование для НКП. У большинства пациентов (70\%), включенных в данный реестр отмечался III или IV функциональный класс стенокардии напряжения, а $62 \%$ пациентов принимали нитроглицерин. 671 пациент $(68,6 \%)$ в данном исследовании были признаны неподходящими для дальнейших процедур реваскуляризации миокарда, в то время как, 307 пациентов (31,4\%) подходили для процедур реваскуляризации (ангиопластики или аорто- 
коронарного шунтирования). В этом исследовании была реализована концепция использования НКП в дополнение к оптимальной медикаментозной терапии у пациентов со стабильной стенокардией напряжения и подходящих для процедур реваскуляризации миокарда. НКП для пациентов, подходящих для реваскуляризации была выполнена по причине того, что пациенты или отказывались от инвазивных процедур, или же хотели их отсрочить. После окончания курса лечения у 80,8\% больных отмечалось снижение функционального класса стенокардии как минимум на один функциональный класс. У большинства больных отмечалось снижение числа приступов стенокардии, уменьшение частоты приема нитроглицерина, а также улучшение качества жизни [20].

Немаловажное значение на дальнейшее внедрение в клиническую практику метода НКП оказали влияние и те исследования, в которых изучалась эффективность НКП при длительном наблюдении за пациентами. Наибольшее количество пациентов, которые наблюдались 3 года после окончания курса лечения НКП, было в исследовании Международного регистра пациентов НКП. У большинства пациентов до курса лечения НКП регистрировался III или IV ФК стенокардии (у 89,2\%). Сразу после окончания лечения у $77,9 \%$ пациентов отмечалось снижение ФК стенокардии на один и выше функциональный класс. Через 3 года данный показатель составил 74\%, т.е. терапевтический эффект НКП у большинства пациентов сохранялся в течение 3 -х лет (Рисунок 1) [21].

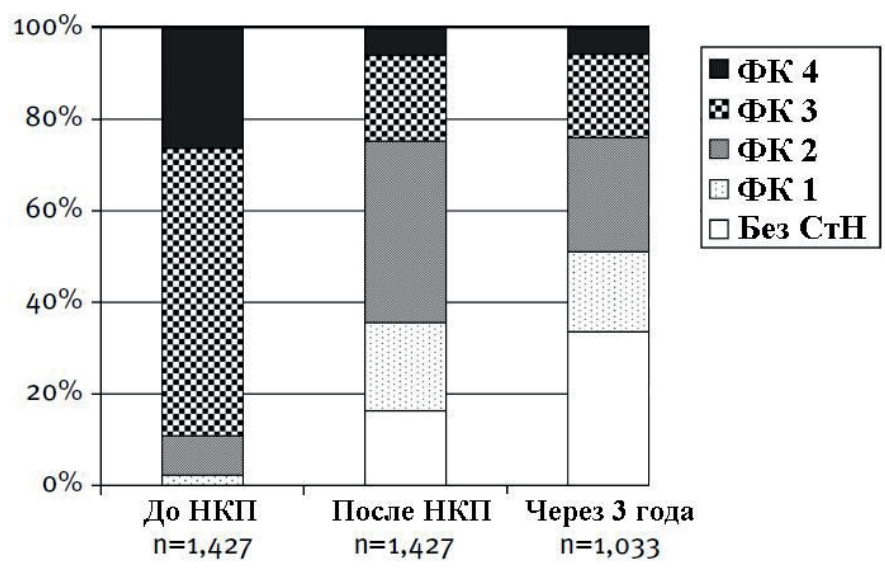

Рисунок 1 - Изменение функционального класса (ФК) стенокардии напряжения $(\mathrm{CTH})$ до лечения (левая диаграмма), сразу после лечения (центральная диаграмма) и через 3 года после завершения курса лечения НКП (правая диаграмма).

В 2013 году НКП была включена в официальные рекомендации Европейского Общества Кардиологов (ESC). Метод получил класс рекомендаций IIа, при уровне доказательной базы В. Европейское общество кардиологов рекомендовало использование НКП для симптоматического лечения пациентов с тяжелой стенокардией, рефрактерной к медикаментозной терапии и процедурам реваскуляризации миокарда [5].

\section{Гемодинамические эфффекты НКП}

Во время НКП наружное, механическое, компрессионное воздействие на нижние конечности приводит к ряду положительных гемодинамических эффектов на сердечно-сосудистую систему. Если обобщить, то эти эффекты в какой-то мере схожи с гемодинамическими эффектами внутриаортальной баллонной контрпульсации, и обусловлены основными двумя эффектами: диастолическим усилением кровотока и систолической разгрузкой левого желудочка. Последовательная, дистально-проксимальная компрессия артериальной системы нижних конечностей, осуществляемая в диастолу, вызывает ретроградный ток крови из артерий нижних конечностей в аорту. Выраженное увеличение системного диастолического давления увеличивает кровоснабжение различных органов [22]. Особенно это актуально для коронарного кровотока, который получает большую часть своего кровоснабжения во время диастолы. Инвазивное исследование гемодинамического влияния НКП на коронарный кровоток было выполнено Michaels и cоавтр. Как показало это исследование, во время НКП увеличивается пиковое диастолическое интракоронарное давление на 93\%, площадь под кривой интракоронарного диастолического давления на 28\%, и среднее интракоронарное давление на $16 \%$, в то время как пиковая диастолическая Допплеровская скорость кровотока увеличивается на 150\% (Рисунок 2) [23].

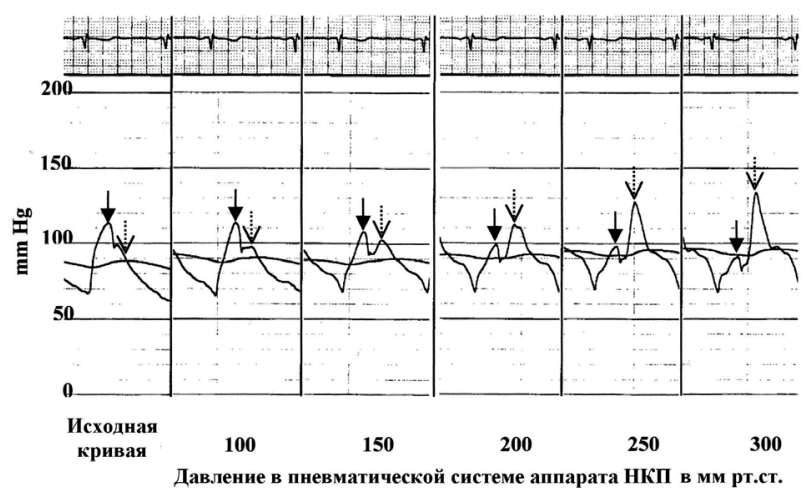

Рисунок 2 - Варианты кривых интракоронарного давления исходно (самая левая кривая), и по мере повышения давления в пневматической системе аппарата НКП (кривые слева направо). По мере увеличения давления компрессии, увеличивается диастолическое давление в коронарных сосудах (пунктирная стрелка), в то время как систолическое давление уменьшается (сплошная стрелка) [23].

\section{Технические аспекты проведения НКП}

Для осуществления наружной контрпульсации используют специально разработанные аппараты (Рисунок 3).

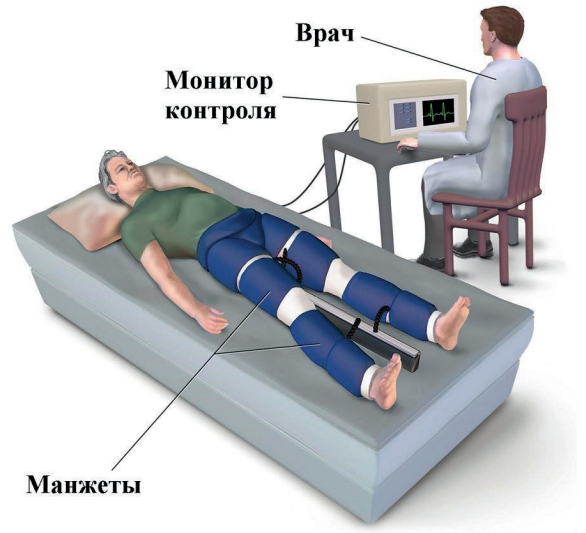

Рисунок 4 - Схема аппарата для проведения НКП. Пациент ложится на специальную кушетку, из которой исходят шланги подачи воздуха в манжеты, накладываемые на нижние конечности пациента. Контроль работы аппарата осуществляется врачом с помощью монитора контроля. 
Гемодинамическое воздействие на пациента оказывается при помощи трех пар пневматических манжет, которые плотно накладываются на икры, бедра и ягодицы пациента. Во время работы аппарата НКП на основе сигнала ЭКГ пациента эти три пары манжет надуваются строго во время диастолы (после зубца R на ЭКГ), последовательно (дистально-проксимально) и очень быстро, создавая таким образом компрессию сосудистой системы нижних конечностей. В конце диастолы, перед самым началом систолы (до следующего зубца R на ЭКГ) воздух из всех пар манжет мгновенно стравливается - создавая, таким образом, декомпрессию сосудистой системы нижних конечностей (Рисунок 4).

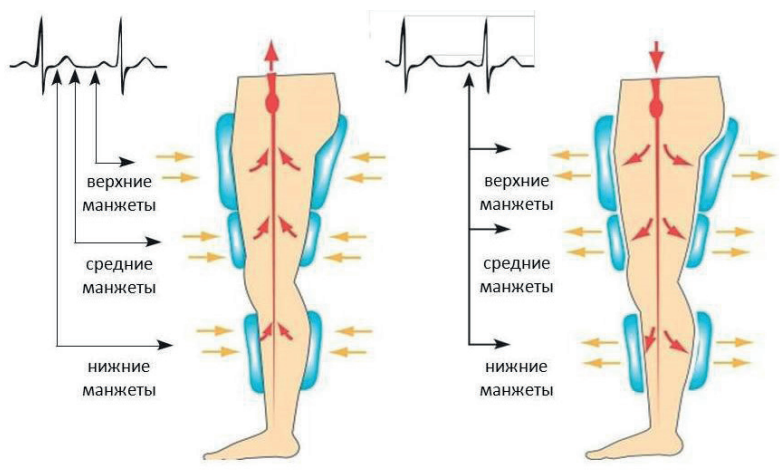

Рисунок 4 - Принцип работы аппарата НКП. Во время диастолы (левый рисунок) происходит последовательная компрессия пневматических манжет, накладываемых на икры, бедра и ягодицы пациента. Начало компрессии строго контролируется на основе сигналов ЭКГ. В конце диастолы, перед самым началом систолы (правый рисунок) происходит одномоментное выкачивание воздуха из всех манжет (создается декомпрессия).

Компрессионное давление в манжетах обычно находится в пределах 250-300 мм рт.ст., с целью достижения оптимального гемодинамического эффекта с минимальным риском баротравмы. Как компрессия, так и декомпрессия всех манжет полностью автоматизирована, и зависит от ЭКГ пациента, находящегося на лечебной кушетке аппарата НКП. ЭКГ пациента используется микропроцессорной системой аппарата НКП для начала компрессии и декомпрессии манжет. Оптимальное время компрессии и декомпрессии обычно регулируется в ручном режиме с целью достижения оптимального диастолического усиления и систолической разгрузки миокарда. Для контроля гемодинамических эффектов НКП используется пальцевая плетизмограмма пациента.

\section{Режим лечения}

Полный курс лечения НКП состоит из 35 сеансов, каждый из которых длится 1 час. Обычно курс лечения проходит в течение 6-7 недель, по 5-6 сеансов каждую неделю. Выбор именно этого режима лечения основывается на ранних работах доктора Zheng и др., которые при лечении 15 больных с ишемической болезнью сердца отметили постепенное увеличение толерантности к физической нагрузке после 12, 24 и 36 часов лечения. После 36 часов лечения наступала, так называемая фаза «плато», когда дополнительные часы терапии НКП не приводили к улучшению толерантности к физической нагрузке [10]. В некоторых случаях курс лечения может состоять из 2-х сеансов в день, в таком случае весь курс лечения занимает в среднем от 3-х до 4-х недель. В этом случае первые 5 сеансов делают по одному часу в день, а оставшиеся 30 по 2 сеанса в день, но с условием как минимум 1 часа перерыва между сеансами. Такой режим также считается эффективным, но он не сравнивался по эффективности с обычным курсом лечения на достаточно большом количестве пациентов. Также необходимо указать на то, что у тех пациентов, у которых не наблюдается выраженного клинического улучшения через 35 часов лечения, курс лечения может быть безопасно продолжен. Те пациенты, у которых наблюдается ухудшение симптоматики, могут получить дополнительный, повторный курс лечения НКП с хорошим симптоматическим эффектом в большинстве случаев [24].

\section{Показания к НКП}

На данный момент Управление по санитарному надзору за качеством пищевых продуктов и медикаментов в США (FDA) разрешило использовать НКП для лечения хронической сердечной недостаточности, стабильной и нестабильной стенокардии, острого инфаркта миокарда и кардиогенного шока. Однако, в современной кардиологической практике данная методика используется в основном для лечения стабильной рефрактерной стенокардии напряжения, а также в некоторых случаях для лечения хронической сердечной недостаточности [25]. Таким образом, НКП следует использовать для пациентов с рефрактерной стенокардией, получающих оптимальную медикаментозную терапию, а также у тех пациентов, которые, по мнению лечащего кардиолога или же кардиохирурга не являются кандидатами для повторных процедур реваскуляризации миокарда [26, 27]. НКП также может быть использована у пациентов, отказывающихся от процедур реваскуляризации миокарда, а также в тех случаях, когда есть необходимость в отсрочке процедур реваскуляризации.

Еще одним важным и перспективным показанием к НКП является кардиальный синдром X. Проблема кардиального синдрома X имеет немаловажное значение в современной кардиологической практике. Под кардиальным синдромом X подразумевается болевой синдром в грудной клетке по типу ангинозных болей, депрессия ST-сегмента во время проведения стресс-ЭКГ теста, но при проведении коронарной ангиографии гемодинамически значимые стенозы в коронарных артериях не обнаруживаются. Кардиальный X синдром наиболее часто регистрируется у женщин после менопаузы. Исторически кардиальный X синдром считался доброкачественным состоянием, однако по последним сообщениям у пациентов с кардиальным синдромом $\mathrm{X}$ чаще наблюдаются неблагоприятные кардиологические события, также у этой категории пациентов отмечается ухудшение показателей качества жизни [28]. Кардиальный синдром Х наблюдается у 3-11\% пациентов, направляемых на коронарную ангиографию [29]. НКП является одним из методов лечения кардиального синдрома Х. В исследовании, выполненном Kronhaus и соавтр. приняли участие 30 пациентов (22 женщины и 8 мужчин) с рефрактерной стенокардией, причиной которой был признан кардиальный синдром Х. После окончания курса лечения НКП, все больные отметили улучшение функционального класса стенокардии: у 8 пациентов на 1 класс, у 10 пациентов на 2 класса, а у 12 пациентов на 3 класса. Таким образом, у большинства пациентов (73\%) класс стенокардии улучшился на 2 и более классов: 
в среднем с 3,57 до 1,43 (p<0,001). Лечебный эффект сохранялся у $87 \%$ пациентов в течение года, остальные $13 \%$ пациентов получили повторный курс НКП с положительным результатом [30]. Таким образом, НКП также может быть использована для лечения пациентов с кардиальным синдромом X.

\section{Меры предосторожности и противопока- зания к НКП}

Несмотря на то, что НКП является неинвазивным методом лечения с незначительным числом серьезных побочных эффектов, ряд предосторожностей должен быть учтен, особенно в некоторых клинических ситуациях. НКП противопоказана у пациентов со средней и тяжелой аортальной недостаточностью. У этих пациентов наличие гемодинамически значимой аортальной недостаточности приводит к снижению эффективности НКП - снижается степень диастолического усиления из-за того, что часть крови в диастолу вместо коронарных артерий возвращается в левый желудочек. Следует учитывать еще и то, что у пациентов с гемодинамически значимой аортальной недостаточностью при сеансе НКП увеличивается степень аортальной недостаточности из-за повышения диастолического давления в аорте. Это может привести к значимому повышению конечно-диастолического давления в левом желудочке, и как следствие этого отеку легких. В противоположность аортальной недостаточности, пациенты с аортальным или митральным стенозом могут безопасно принимать лечение НКП, даже, несмотря на предположение о том, что увеличение преднагрузки может привести к застою в легких, и как следствие этого к отеку легких или же к сердечной недостаточности [25].

НКП является безопасным методом лечения у пациентов с сердечной недостаточностью, однако метод НКП противопоказан пациентам с декомпенсацией сердечной недостаточности, и особенно у пациентов с легочной гипертензией. Также НКП противопоказана пациентам с хроническим легочным сердцем.

Процессы компрессии и декомпрессии во время НКП осуществляются на основе ЭКГ сигнала пациента, благодаря которому микропроцессорная система аппарата рассчитывает время начала компрессии и декомпрессии. Время начала декомпрессии программа аппарата НКП рассчитывает эмпирически на основе длительности предыдущих циклов ЭКГ, что требует наличия стабильного ритма у пациента с постоянными интервалами R-R на ЭКГ. Поэтому такие аритмии как, частая экстрасистолия (как желудочковая, так и предсердная), мерцание и трепетание предсердий приводят к нарушению нормального ритма работы аппарата НКП. Отдельно следует указать о возможности НКП у пациентов с установленным постоянным кардиостимулятором, или же имплантируемым кардиовертер-дефибриллятором. У этих пациентов НКП в большинстве случаев безопасна, однако следует учитывать режим работы постоянного кардиостимулятора, который в некоторых случаях требует деактивации ряда функций, что требует консультации лечащего врача-аритмолога.

Выраженная гипертония является противопоказанием к НКП, так как НКП может еще больше повысить диастолическое давление. Максимально допустимым систолическим давлением обычно считают 180 мм рт. ст, тогда как диастолическое давление не должно превышать значения 110 мм рт. ст. Следует, однако признать, что эти цифры артериального давления условны и для некоторых пациентов могут быть другими. При наличии у пациента гипертонии до начала лечения НКП должно быть назначено соответствующее медикаментозное лечение, позволяющее адекватно контролировать артериальное давление.

Выраженное, тяжелое облитерирующее заболевание артерий нижних конечностей может снижать эффективность НКП из-за сниженного объема сосудистого русла, и общей массы мускулатуры нижних конечностей. Это приводит к снижению степени диастолического усиления кровотока. Облитерирующие заболевания артерий нижних конечностей являются противопоказанием к НКП, особенно если пациент испытывает неприятные ощущения или боли в нижних конечностях. Наличие аневризмы брюшной аорты является противопоказанием к НКП, так как увеличение диастолического и среднего артериального давления может привести к прогрессированию размеров аневризмы.

Пациенты, перенесшие инвазивные кардиологические процедуры должны начать лечение НКП после завершения процесса заживления в месте используемого сосудистого доступа. Рекомендовано начинать курс лечения НКП после одного или двух недельного перерыва после процедуры пункции бедренной артерии. Также рекомендован 3-х месячный перерыв после операции аорто-коронарного шунтирования. В случае пункции бедренной артерии необходимо исключить возможные местные осложнения в месте пункции, такие как: подкожная гематома и вторичное кровотечение из места пункции сосуда, забрюшинная гематома, тромбоз бедренной артерии, образование аневризмы в месте пункции, экстравазаты контрастного вещества.

НКП противопоказана пациентам с тромбозом глубоких вен или тромбофлебитом вен нижних конечностей из-за потенциального риска тромбоэмболии легочной артерии. Меры предосторожности должны быть приняты у пациентов с геморрагическим диатезом, или же находящихся на антикоагулянтном лечении. В случаях невозможности отмены антикоагулянтов на время лечения КНП, необходима коррекция их дозы, так чтобы международное нормализованное отношение (INR) не превышало показателя 2,0. НКП также противопоказана при беременности, из-за возможно потенциального вреда для плода.

\section{Заключение}

Для лечения рефрактерной стенокардии было предложенобольшоеколичество различныхметодовлечения. Среди этих методов лечения НКП является безопасной, полностью неинвазивной, клинически и экономически эффективной методикой лечения. Применение курса НКП у больных с рефрактерной стенокардией позволяет уменьшить тяжесть приступов стенокардии, улучшить качество жизни пациентов, увеличить переносимость физических нагрузок, а также улучшить объективные проявления ИБС. Методика НКП является ценным дополнением к стандартной медикаментозной терапии больных со стабильной стенокардией напряжения, особенно у больных с выраженной клиникой стенокардии, при невозможности по тем или иным причинам выполнения инвазивного лечения, после процедур реваскуляризации миокарда в случае 
невозможности повторных вмешательств, при кардиальном синдроме X и вазоспастической стенокардии, а также при систолической сердечной недостаточности ишемической этиологии.
Методика хорошо переносится пациентами, и может быть использована в амбулаторных условиях.

Disclosures: There is no conflict of interest for all authors.

\section{Список литературы}

1. WHO Mortality Database, May 2014 update. World Health Organization, Department of Health Statistics and Information Systems, Geneva, Switzerland. World Health Organization, 2014. http://www.who.int/healthinfo/statistics/mortality_rawdata/en/ index.html.

2. Zaher C, Goldberg GA, Kadlubek P. Estimating angina prevalence in a managed care population. Am J Manag Care. 2004 Oct;10(11 Suppl):S339-346.

3. Hilton TC, Chaitman BR. The prognosis in stable and unstable angina. Cardiol Clin. 1991 Feb;9(1):27-38.

4. Kevin Cheng, Paul Sainsbury, Michael Fisher, Ranil de Silva. Management of refractory angina pectoris. European Cardiology Review 2016;11(2):69-76.

5. Montalescot G, Sechtem U, Achenbach S, Andreotti F, Arden C, Budaj A, Bugiardini R, Crea F, Cuisset T, Di Mario C, Ferreira JR, Gersh BJ, Gitt AK, Hulot JS, Marx N, Opie LH, Pfisterer M, Prescott E, Ruschitzka F, Sabaté M, Senior R, Taggart DP, van der Wall EE, Vrints CJ. 2013 ESC guidelines on the management of stable coronary artery disease. European Heart Journal 2013;34:2949-3003.

6. Kantrowitz A., Kantrowitz A. Experimental augmentation of coronary flow by retardation of arterial pressure pulse. Surgery 1953;34:678-687.

7. Dennis C, Moreno JR, Hall DP, Grosz C, Ross SM, Wesolowski SA, Senning A. Studies external counterpulsation as a potential measure for acute left heart failure. Trans Am Soc Artif Intern Organs. 1963;9:186-191.

8. Birtwell W, Giron F, Soroff H, Ruiz U, Collins J, Deterling R. Support of the Systemic Circulation and Left Ventricular Assist by Synchronous Pulsation of Extramural Pressure. Trans Am Soc Artif Intern Organs. 1965;11:43-51.

9. Giron F, Birtwell WC, Soroff HS, Ruiz U, Collins JA, Deterling RA, Jr. Assisted circulation by synchronous pulsation of extramural pressure. Surgery 1966;60:894-901.

10. Zheng ZS, Li TM, Kambic H, Chen GH, Lu LQ, Cai SR, Zhan CY, Chen YC, Wo SX, Chen GW. Sequential external counterpulsation (SECP) in China. Trans Am Soc Artif Intern Organs. 1983;29:599-603.

11. Soroff HS, Birtwell WC. Clinical evaluation in synchronous external counterpulsation in cardiogenic shock. J Cardiovasc Surg (Torino). 1973;Spec No:752-756.

12. Soroff HS, Cloutier CT, Birtwell WC, Begley LA, Messer JV. External counterpulsation. Management of cardiogenic shock after myocardial infarction. Jama. 1974;229:1441-1450.

13. Amsterdam EA, Banas J, Criley JM, Loeb HS, Mueller H, Willerson JT, Mason DT. Clinical assessment of external pressure circulatory assistance in acute myocardial infarction. Report of a cooperative clinical trial. Am J Cardiol. 1980;45:349-356.

14. Cloutier CT, Soroff HS, Giron F, Birtwell WC, Messer JV, Ryan TJ, Flessas A, Lutten C, Evans GL, Ehrich DA, Waltuch T, Hoell JF. The physiologic effects of synchronous external circulatory assistance in patients in cardiogenic shock. Surg Forum. 1971;22:187-188.

15. Cloutier CT, Soroff HS, Birtwell WC, Banas JS, Brilla AH, Begley LA, Childs P, Messer JV. Clinical evaluation of synchronous external circulatory assistance in cardiogenic shock. Surg Forum. 1972;23:170-172.

16. Banas J.S., Brilla A., Soroff H.S.. Evaluation of external counterpulsation for treatment severe angina pectoris. Circulation 1972;46(Suppl II):II-74.

17. Lawson WE, Hui JCK, Soroff HS, et al. Efficacy of enhanced external counterpulsation in the treatment of angina pectoris. The American Journal of Cardiology 1992;70:859-862.

18. Arora RR, Chou TM, Jain D, Fleishman B, Crawford L, McKiernan T, Nesto RW. The multicenter study of enhanced external counterpulsation (MUST-EECP): effect of EECP on exercise-induced myocardial ischemia and anginal episodes. J Am Coll Cardiol. 1999;33:1833-1840.

19. Lawson WE, Hui JC, Lang G. Treatment benefit in the enhanced external counterpulsation consortium. Cardiology 2000; 94:3135 .

20. Barsness G, Feldman AM, Holmes DR, Holubkov R, Kelsey SF, Kennard ED, Investigators TIEPR. The International EECP Patient Registry (IEPR): Design, methods, baseline characteristic, and acute results. Clin Cardiol. 2001;24:435-442.

21. PH Loh, JGF Cleland, AA Louis, ED Kennard, J Cook, JL Caplin, GW Barness, WE Lawson, OZ Soran, AD Michaels, for the IEPR Investigators. Enhanced external counterpulsation (EECP) in the treatment of chronic refractory angina: a long-term follow-up outcome from the International EECP Patient Registry (IEPR). Clin Cardiol. 2008;31(4):159-164.

22. Werner D, Schneider M, Weise M, et al. Pneumatic external counterpulsation: a new noninvasive method to improve organ perfusion. Am J Cardiol. 1999;84(8):950-952.

23. Michaels AD, Accad M, Ports TA, Grossman W. Left ventricular systolic unloading and augmentation of intracoronary pressure and Doppler flow during enhanced external counterpulsation. Circulation 2002;106:1237-1242.

24. Lawson WE, Barsness G, Michaels AD, Soran O, Kennard ED, Kelsey SF, Hui JC. Effectiveness of repeat enhanced external counterpulsation for refractory angina in patients failing to complete an initial course of therapy. Cardiology 2007;108:170-175.

25. Lawson WE. Current use of enhanced external counterpulsation and patient selection. Clin Cardiol. 2002;25:II16-21.

26. Mannheimer C, Camici P, Chester MR, Collins A, DeJongste M, Eliasson T, Follath F, Hellemans I, Herlitz J, Luscher T, Pasic M, Thelle D. The problem of chronic refractory angina; report from the ESC Joint Study Group on the Treatment of Refractory Angina. Eur Heart J. 2002;23:355-370. 
27. Fihn SD, Gardin JM, Abrams J, Berra K, Blankenship JC, Dallas AP, Douglas PS, Foody JM, Gerber TC, Hinderliter AL, King SB, 3rd, Kligfield PD, Krumholz HM, Kwong RY, Lim MJ, Linderbaum JA, Mack MJ, Munger MA, Prager RL, Sabik JF, Shaw LJ, Sikkema JD, Smith CR, Jr., Smith SC, Jr., Spertus JA, Williams SV. 2012 ACCF/AHA/ACP/AATS/PCNA/SCAI/STS guideline for the diagnosis and management of patients with stable ischemic heart disease: executive summary: a report of the American College of Cardiology Foundation/American Heart Association task force on practice guidelines, and the American College of Physicians, American Association for Thoracic Surgery, Preventive Cardiovascular Nurses Association, Society for Cardiovascular Angiography and Interventions, and Society of Thoracic Surgeons. Circulation 2012;126:3097-3137.

28. Agrawal S, Mehta P.K., Bairey Merz C.N. Cardiac Syndrome X - Update 2014. Cardiol Clin. 2014 August;32(3):463-478.

29. Vermeltfoort IA, Raijmakers PG, Riphagen II, Odekerken DA, Kuijper AF, Zwijnenburg A, Teule GJ. Definitions and incidence of cardiac syndrome X: review and analysis of clinical data. Clin Res Cardiol. 2010 Aug;99(8):475-481.

30. Kronhaus KD, Lawson WE. Enhanced External Counterpulsation is an effective treatment for syndrome X. Int J Cardiol. 2009;135(2):256-257.

How to cite this article: Rovshan Huseyn Alakbarov, Tofig Shahmur Jahangirov, Orazbek Sakhov, Sholpan Zhangelova. External counterpulsation for the treatment of patients with refractory angina [in Russian]. J Clin Med Kaz. 2018; 2(48):14-21 